\title{
Carotid atherosclerosis-related mutations of mitochondrial DNA do not explain the phenotype of metabolic syndrome
}

\author{
Igor A. Sobenin ${ }^{1,2}$, Jukka T. Salonen ${ }^{3,4}$, Zukhra B. Khasanova1, Vasily V. Sinyov', Tatiana V. Kirichenko ${ }^{1,5}$ \\ Alexandra A. Melnichenko ${ }^{1}$, Alexandra I. Prokudina ${ }^{1}$, Varvara A. Orekhova ${ }^{1}$, Andrey V. Grechko ${ }^{6}$ \\ 'Laboratory of Medical Genetics, National Medical Research Center of Cardiology, Moscow 121552, Russia. \\ ${ }^{2}$ Laboratory of Angiopathology, Institute of General Pathology and Pathophysiology, Moscow 125315, Russia. \\ ${ }^{3}$ Department of Public Health, Faculty of Medicine, University of Helsinki, Helsinki Fl-00014, Finland. \\ ${ }^{4}$ MAS-Metabolic Analytical Services Oy, Helsinki Fl-00990 Finland. \\ ${ }^{5}$ Institute for Atherosclerosis Research, Skolkovo Innovation Center, Moscow 143025, Russia. \\ ${ }^{6}$ Federal Scientific Clinical Center for Resuscitation and Rehabilitation, Moscow 109240, Russia.
}

Correspondence to: Dr. Igor A. Sobenin, Laboratory of Medical Genetics, National Medical Research Center of Cardiology, 15-a, 3-rd Cherepkovskaya Str., Moscow 121552, Russia. E-mail: igor.sobenin@gmail.com

How to cite this article: Sobenin IA, Salonen JT, Khasanova ZB, Sinyov VV, Kirichenko TV, Melnichenko AA, Prokudina AI, Orekhova VA, Grechko AV. Carotid atherosclerosis-related mutations of mitochondrial DNA do not explain the phenotype of metabolic syndrome. Vessel P/us 2019;3:14. http://dx.doi.org/10.20517/2574-1209.2018.63

Received: 22 Aug 2018 First Decision: 10 Jan 2019 Revised: 12 Feb 2019 Accepted: 19 Feb 2019 Published: 21 Apr 2019

Science Editor: Igor A. Sobenin Copy Editor: Cai-Hong Wang Production Editor: Huan-Liang Wu

\begin{abstract}
Aim: This study was undertaken to explore the relationship between metabolic syndrome (MetS) and atherosclerosisrelated mitochondrial DNA (mtDNA) mutations, since MetS shares conventional and genetic risk factors with atherosclerosis.
\end{abstract}

Methods: The study involved 220 participants; the carotid ultrasonography followed by intima-media thickness (cIMT) measurement was used for quantitative diagnostics of carotid atherosclerosis. The diagnosis of MetS was set according to International Diabetes Federation criteria (IDF-2009). The level of mtDNA heteroplasmy in leukocytes was determined by qPCR. The severity of MetS was estimated on combination of serum HDL cholesterol, triglycerides and fasting glucose, systolic and diastolic blood pressure, and waist circumference measurements.

Results: MetS was present in 44 study participants. Ten mtDNA mutations were tested, and m.3336T>C and m.652delG heteroplasmy levels correlated with the clusterization of MetS symptoms, in particular the cardiovascular and metabolic risk factors, of triglyceride and fasting glucose levels. The other mtDNA mutations each only correlated with one symptom (i.e., m.652delG and m.12315G>A-with triglycerides; m.3256C>T, m.1555A>G, and m.15059G>A-with systolic blood 
pressure; m.14846G>A-with fasting glucose). There was no correlation between integral severity of MetS and cIMT.

Conclusion: In this study, the MetS phenotype was not explained directly by atherosclerosis-related mtDNA variants. It is possible to hypothesize that mtDNA-related mechanisms in atherosclerosis and MetS may be different, in spite of the similarity of several phenotypic characteristics.

Keywords: Metabolic syndrome, carotid atherosclerosis, mitochondrial DNA mutations, risk factors

\section{INTRODUCTION}

Excessive body mass, obesity, metabolic syndrome (MetS) and Type 2 diabetes are metabolic disturbances affecting the population, often occurring in parallel with atherosclerosis development, contributing to morbidity. All of these pathologies are characterized by excessive deposition of body fat and health impairment. Cardiovascular and metabolic diseases are in part of genetic, in part of behavioral origin. Genetic influences are either hereditary or due to somatic (acquired) mutations. Pathogenic mutations can occur either in the nuclear DNA or in the mitochondrial DNA (mtDNA). A number of genome-wide association studies (GWAS) have been carried out in order to discover genes related to metabolic diseases ${ }^{[1-4]}$. However, commercially available GWAS arrays used in such studies rarely cover mitochondrial variants in the population very well. Therefore, the role of mitochondrial genes in metabolic diseases has been less well studied, even though the mitochondria play the definitive role in energy production and metabolism, and in the development of oxidative stress. Despite the ever increasing prevalence and high heritability of atherosclerosis and metabolic diseases, as well as intensive and long research efforts, the causal genes remain poorly known. Mitochondria are the center of energy metabolism in the human body; therefore, variations of their genes and function are expected to influence metabolism and reactive oxygen species (ROS) production.

Epidemiological and clinical studies have revealed a clustering of conventional cardiovascular risk factors including obesity, MetS, Type 2 diabetes mellitus, atherosclerosis, and coronary artery disease. Each conventional risk factor alone increases the risk of clinical manifestations of atherosclerosis with the combination of several risk factors exacerbating clinical sequelae. This is also true in the setting of MetS, with multiple risk factors resulting in heightened risk of atherosclerotic disease together with cardiometabolic abnormalities. MetS is also generally defined in clinical studies and clinical practice as a cluster of risk factors associated with Type 2 diabetes mellitus and cardiovascular disease ${ }^{[5-10]}$. It is further generally recognized that conventional risk factors possess a significant genetic component, but the evidence of the role of genetic factors in risk factor clustering in individuals remains uncertain ${ }^{[1]}$.

It has recently been shown that several mutations of mtDNA are associated with atherosclerosis. Namely, heteroplasmic mutations m.652delG, m.1555A $>$ G, m.3336T $>C, m .3256 \mathrm{C}>\mathrm{T}, \mathrm{m} .5178 \mathrm{C}>\mathrm{A}, \mathrm{m} .12315 \mathrm{G}>\mathrm{A}$, m.13513G $>A, m .14459 \mathrm{G}>\mathrm{A}, \mathrm{m} .14846 \mathrm{G}>\mathrm{A}$, and $\mathrm{m} .15059 \mathrm{G}>\mathrm{A}$ were found in atherosclerotic plaques of human aortic intima, and there were significant differences in the heteroplasmy level between unaffected and atherosclerotic tissues. These mutations occurred in mitochondrial genes MT-RNR1 (rRNA 12S); MT-TL1 and MT-TL2 (tRNA-Leu); MT-ND1, MT-ND2, MT-ND5, and MT-ND6 (subunits 1, 2, 5 and 6, of NADH dehydrogenase, respectively), and MT-CYB (cytochrome b $)^{[12-15]}$. Further, most of these mutations were found to be associated with the severity of carotid atherosclerosis and, with lesser extent, the presence of coronary heart disease $\mathrm{e}^{[16-20]}$.

Since MetS shares common risk factors with atherosclerosis and, moreover, is considered itself as the independent risk factor for atherosclerosis, this study was performed to test the hypothesis that MetS and atherosclerosis-related heteroplasmic mtDNA mutations are associated. 


\section{METHODS}

\section{Patients}

This study was kept in accordance with the Helsinki Declaration of 1975 as revised in 1983, 2008 and 2013, and was approved by the local ethics committee. The study participants were recruited from the visitors' flow at municipal outpatient clinics, who have passed a routine screening for cardiovascular risk factors. In total, 220 study participants were recruited (97 men, 123 women) with a mean age of 65.1 years (SD 9.4). The written informed consent was obtained from all participants prior to inclusion in the study.

\section{MetS diagnostics}

For identification of patients with clustered risk factors and MetS, IDF 2009 criteria were used $^{[10]}$. In brief, waist circumference $>94 \mathrm{~cm}$ in men and $>88 \mathrm{~cm}$ in women, triglycerides $\geq 150 \mathrm{mg} / \mathrm{dL}$ or drug treatment for elevated triglycerides, HDL cholesterol $\leq 40 \mathrm{mg} / \mathrm{dL}$ in men and $\leq 50 \mathrm{mg} / \mathrm{dL}$ in women, or drug treatment for reduced HDL cholesterol, systolic blood pressure $\geq 150 \mathrm{mmHg}$ and/or diastolic blood pressure $\geq 85 \mathrm{mmHg}$, or antihypertensive drug treatment, and fasting glucose $\geq 5.6 \mathrm{mmol} / \mathrm{L}$ or drug treatment of elevated glucose were taken in consideration. The presence of at least 3 of above criteria was required for the diagnosis of MetS. The group of MetS-free study participants consisted of subjects who had 0-1 of the above criteria. The subjects with 2 MetS criteria were not eligible for inclusion in the study to avoid possible uncertainties. To formally describe the severity of MetS (the extent of clusterization of conventional risk factors), an unofficial integral MetS index was calculated as a simple multiplication of the absolute values of waist circumference, triglycerides, systolic and diastolic blood pressure, and fasting glucose, divided by HDL cholesterol.

\section{Ultrasonographic examination}

For diagnostics of carotid atherosclerosis, high-resolution B-mode carotid arterial ultrasonography imaging was used (SSI-6000 ultrasound system, SonoScape, China, equipped by 7.5-MHz L741 linear array probe). The protocol of ultrasound examination developed earlier by Salonen et al. ${ }^{[21]}$, 1995 was used. The cIMT measurements were carried out with M'Ath software package (IMT, France). The extent of carotid atherosclerosis and the size of atherosclerotic plaques were evaluated as described elsewhere ${ }^{[17,22]}$.

\section{MtDNA genotyping}

DNA was isolated from circulating leukocytes (whole venous blood) using a commercial kit for DNA isolation and purification (QIAGEN GmbH, Germany) according to manufacturer's instructions. DNA concentration in samples was determined by NanoPhotometer Pearl UV/Vis SDRAM P-34 (IMPLEN, Germany); the samples were kept in TE buffer at a concentration of $0.03 \mu \mathrm{g} / \mu \mathrm{L}$. Heteroplasmy levels of mtDNA mutations m.652delG, m.1555A $>\mathrm{G}, \mathrm{m} .3336 \mathrm{~T}>\mathrm{C}, \mathrm{m} .3256 \mathrm{C}>\mathrm{T}, \mathrm{m} .5178 \mathrm{C}>\mathrm{A}, \mathrm{m} .12315 \mathrm{G}>\mathrm{A}, \mathrm{m} .13513 \mathrm{G}>\mathrm{A}$, m.14459G $>$ A, m.14846G $>$ A, and m.15059G $>$ A were analyzed on Real Time PCR System 7500 Fast (Applied Biosystems, USA) by qPCR (5'-terminal tag excision, TaqMan Assay). The nucleotide sequences for primers and probes are shown in Table 1.

For qPCR, $4 \mu \mathrm{L}$ DNA was added to $25 \mu \mathrm{L}$ of standard reaction mixture [1x TaqMan Buffer, $3 \mathrm{mmol} / \mathrm{L} \mathrm{MgCl}_{2}$, $250 \mu \mathrm{mol} / \mathrm{L}$ of each dNTP, $300 \mathrm{nmol} / \mathrm{L}$ primers, $300 \mathrm{nmol} / \mathrm{L}$ hybridization probes, 0.5 units Taq-polymerase (Helicon, Moscow, Russia)]. Denaturation was held for $2 \mathrm{~min}$ at $94^{\circ} \mathrm{C}$; amplification stage with fluorescence detection included denaturation for $10 \mathrm{~s}$ at $94^{\circ} \mathrm{C}$, and annealing for $15 \mathrm{~s}$ at a temperature specified for each pair of primers and probes (range $61^{\circ} \mathrm{C}-67^{\circ} \mathrm{C}$ ).

\section{Statistical analysis}

The statistical analysis was done using the IBM SPSS 22.0 software package (IBM Corp., Chicago, IL, USA). The methods of descriptive statistics, correlation analysis by Spearman and Pearson, and one-way analysis of variance (ANOVA) were used. Mean values were compared by T-test or U-test by Mann-Whitney for continuous variables, and $\chi^{2}$ Pearson's test for categorical variables. To assess the homogeneity of variance, 
Table 1. Nucleotide sequences for primers and probes for qPCR

\begin{tabular}{|c|c|c|}
\hline Mutation & Primers & Probes \\
\hline m.652delG & $\begin{array}{l}\text { F actgaaaatgtttagacgggct } \\
\text { R ggggatgcttgcatgtgtaa }\end{array}$ & $\begin{array}{l}\text { 5'-ROX- aatagggtttggtcctagcctttctattagctc -BHQ-2-3' } \\
5^{\prime} \text {-FAM- aataggtttggtcctagcctttctattagctc - } \mathrm{BHQ}-1-3^{\prime}\end{array}$ \\
\hline m.1555A > G & $\begin{array}{l}\text { F aggacatttaactaaaacccctacg } \\
\text { R agctacactctggttcgtcca }\end{array}$ & $\begin{array}{l}\text { 5'-ROX- agaggaaacaagtcgtaacatggtaagtgtac - } \mathrm{BHQ}-2-3^{\prime} \\
5^{\prime}-\mathrm{FAM} \text { - agaggagacaagtcgtaacatggtaagtgtac - } \mathrm{BHQ}-1-3^{\prime}\end{array}$ \\
\hline $\mathrm{m} .3256 \mathrm{C}>\mathrm{T}$ & $\begin{array}{l}\text { F atacccacacccacccaag } \\
\text { R aagaagaggaattgaacctctgact }\end{array}$ & $\begin{array}{l}\text { 5'-ROX- gcagagcccggtaatcgtataaaactta -BHQ-2-3' } \\
5^{\prime} \text {-FAM- agagccogtaatcgcataaaacttaaa - } \mathrm{BHQ}-1-3^{\prime}\end{array}$ \\
\hline m.3336T > C & $\begin{array}{l}\text { F acagtcagaggttcaattcctctt } \\
\text { R ttcgttcggtaagcattagga }\end{array}$ & $\begin{array}{l}5^{\prime}-\mathrm{ROX} \text { - tactcctcatcgtacccattctaatcgc }-\mathrm{BHQ}--3^{\prime} \\
5^{\prime}-\mathrm{FAM}-\text { tcctcattgtacccattctaatcgcaat }-\mathrm{BHQ}-2-3^{\prime}\end{array}$ \\
\hline$m \cdot 5178 C>A$ & $\begin{array}{l}\text { F cttaaactccagcaccacgac } \\
\text { R aggcctcctagggagagga }\end{array}$ & $\begin{array}{l}5^{\prime}-\mathrm{ROX} \text { - atctcgcacctgaaacaagataacatga -BHQ-2-3' } \\
5^{\prime} \text {-FAM- cgcacctgaaacaagctaacatgactaa -BHQ-1-3' }\end{array}$ \\
\hline $\mathrm{m} .12315 \mathrm{G}>\mathrm{A}$ & $\begin{array}{l}\text { F cagctatccattggtcttaggc } \\
\text { R ggaagtcagggttagggtggt }\end{array}$ & $\begin{array}{l}\text { 5'-ROX- ccaaaaattttagtgcaactccaaataaaag -BHQ-2-3' } \\
5^{\prime}-\mathrm{FAM} \text { - ccaaaaattttggtgcaactccaaataa -BHQ-2-3' }\end{array}$ \\
\hline m.13513G > A & $\begin{array}{l}\text { F gcagcctagcattagcagga } \\
\text { R atagggctcaggcgtttgt }\end{array}$ & $\begin{array}{l}\text { 5'-ROX- caggtttctactccaaaaaccacatcatc -BHQ-2-3' } \\
5^{\prime} \text {-FAM- caggtttctactccaaagaccacatcatc -BHQ-2-3' }\end{array}$ \\
\hline m.14459G > A & $\begin{array}{l}\text { F ccactaaaacactcaccaagacc } \\
\text { R tttagggggaatgatggttg }\end{array}$ & $\begin{array}{l}\text { 5'-ROX- ctcaggatactcctcaatagccatcactgt -BHQ-2-3' } \\
5^{\prime} \text {-FAM- ggatactcctcaatagccatcgctgtag -BHQ-2-3' }\end{array}$ \\
\hline $\mathrm{m} .14846 \mathrm{G}>\mathrm{A}$ & $\begin{array}{l}\text { F aaccactcattcatcgacctc } \\
\text { R cctgtggtgatttggaggat }\end{array}$ & $\begin{array}{l}\text { 5'-ROX- gcatgatgaaacttcagctcactcctt -BHQ-2-3' } \\
5^{\prime} \text {-FAM- catgatgaaacttcggctcactcctt -BHQ-2-3' }\end{array}$ \\
\hline m.15059G > A & $\begin{array}{l}\text { F caatggcgcctcaatattct } \\
\text { R caggaggataatgccgatgt }\end{array}$ & $\begin{array}{l}\text { 5'-ROX- gggcgaggcctatattacagatcatttct -BHQ-2-3' } \\
\text { 5'-FAM- gcgaggcctatattacggatcatttctc - } \mathrm{BHQ}-2-3^{\prime}\end{array}$ \\
\hline
\end{tabular}

F-Test was used. The data were presented in terms of mean and SD, where appropriate. The significance of differences was defined at the 0.05 level of confidence.

\section{RESULTS}

In total, 220 participants were recruited in the study. Forty-four study participants (20\% of the sample) met the criteria of MetS. The data on anthropometric, clinical and biochemical data are presented in Table 2.

As expected, the two groups differed significantly in parameters taken as the criteria for MetS (waist circumference, the presence of arterial hypertension and Type 2 diabetes mellitus, systolic and diastolic blood pressure, blood glucose, serum triglycerides and HDL cholesterol). Additionally, there was a difference in body mass index, the prevalence of left ventricular hypertrophy, the prevalence of CHD, and family anamnesis of Type 2 diabetes mellitus. At the same time, there were no statistically significant differences in age, smoking, total and LDL cholesterol, and family anamnesis of myocardial infarction and hypertension.

Instrumental data on the extent of carotid atherosclerosis assessed by high-performance ultrasound examination are given in Table 3. Mean cIMT and mean maximum cIMT were significantly higher in MetS patients, thus demonstrating higher predisposition to atherosclerosis in patients with cardiometabolic abnormalities. However, the difference in the extent of carotid atherosclerosis assessed by the size of atherosclerotic plaques did not reach statistical significance. Moreover, the correlation coefficient between cIMT and integral MetS index did not reach statistical significance $(r=0.119, P=0.10)$.

The data on genotyping of mtDNA are given in Table 4. Among 10 mtDNA mutations studied, only heteroplasmy levels for $\mathrm{m} .3336 \mathrm{~T}>\mathrm{C}$ and $\mathrm{m} .14846 \mathrm{G}>\mathrm{A}$ mutations were significantly different between MetS patients and MetS-free study participants. The correlation analysis revealed significant correlations between the severity of MetS assessed by integral MetS index and m.652delG heteroplasmy $(r=0.213, P=0.003)$, and m.3336T $>C$ heteroplasmy $(r=0.323, P<0.001)$, but not $\mathrm{m} .14846 \mathrm{G}>\mathrm{A}$ heteroplasmy.

Several correlations were revealed between mtDNA heteroplasmy and stand-alone components of MetS. Systolic blood pressure correlated with heteroplasmy m.1555A $>\mathrm{G}(r=-0.144, P=0.046), \mathrm{m} .3256 \mathrm{C}>\mathrm{T}(r=$ $0.197, P=0.006)$, and $\mathrm{m} .15059 \mathrm{G}>\mathrm{A}(r=0.218, P=0.002)$. Serum triglycerides correlated with heteroplasmy m.652delG $(r=0.190, P=0.008)$, m.3336T $>\mathrm{C}(r=0.291, P<0.001)$, and $\mathrm{m} .12315 \mathrm{G}>\mathrm{A}(r=0.153, P=0.034)$. 
Table 2. Anthropometric, clinical and biochemical characteristics of study participants

\begin{tabular}{llll}
\hline Variable & MetS-free study participants, $\boldsymbol{n = 1 7 6}$ & MetS patients, $\boldsymbol{n}=\mathbf{4 4}$ & $\boldsymbol{P}$ for the difference \\
\hline Age, years & $65.0(9.9)$ & $65.7(7.5)$ & $\mathrm{NS}$ \\
Gender, m:f & $76: 100$ & $21: 23$ & $\mathrm{NS}$ \\
BMI, kg/m & $25.8(3.9)$ & $30.9(4.8)$ & $<0.001$ \\
Waist circumference, cm & $85.9(4.1)$ & $100.9(5.6)$ & $<0.001$ \\
Systolic BP, mmHg & $146(13)$ & $137(18)$ & $<0.003$ \\
Diastolic BP, mmHg & $81(11)$ & $88(10)$ & $<0.001$ \\
Current smokers, \% & 8 & 11 & $\mathrm{NS}$ \\
Hypertension, \% & 60 & 87 & 0.002 \\
LVH, \% & 31 & 50 & 0.024 \\
T2DM, \% & 4 & 47 & $<0.001$ \\
CHD, \% & 19 & 45 & 0.001 \\
Family history of AMI, \% & 27 & 34 & $\mathrm{NS}$ \\
Family history of HT, \% & 40 & 37 & $\mathrm{NS}$ \\
Family history of T2DM, \% & 13 & 34 & 0.002 \\
Total cholesterol, mg/dL & $240(48)$ & $234(47)$ & $\mathrm{NS}$ \\
Triglycerides, mg/dL & $113(47)$ & $182(72)$ & $<0.001$ \\
LDL cholesterol, mg/dL & $148(43)$ & $144(42)$ & $\mathrm{NS}$ \\
HDL cholesterol, mg/dL & $69(14)$ & $53(14)$ & $<0.001$ \\
Fasting glucose, mmol/L & $5.3(0.9)$ & $6.4(1.1)$ & 0.004 \\
Integral MetS index & $5267(3181)$ & $18069(12495)$ & $<0.001$ \\
\hline
\end{tabular}

Family history, the presence of the disease in first degree relatives diagnosed at age before 60. BMI: body mass index; BP: blood pressure; LVH: left ventricular hypertrophy; T2DM: Type 2 diabetes mellitis; CHD: coronary heart disease; LDL: low density lipoprotein; HDL: high density lipoprotein; AMI: acute myocardial infarction; HT: hypertension; NS: not significant; MetS: metabolic syndrome

Table 3. Characteristics of carotid atherosclerosis

\begin{tabular}{lccc}
\hline Variable & $\begin{array}{c}\text { MetS-free study participants, } \\
\boldsymbol{n}=\mathbf{1 7 6}\end{array}$ & $\begin{array}{c}\text { MetS patients, } \\
\boldsymbol{n}=\mathbf{4 4}\end{array}$ & $\boldsymbol{P}$ for the difference \\
\hline Mean cIMT, mm & $0.853(0.151)$ & $0.935(0.209)$ & 0.006 \\
Mean maximum cIMT, mm & $0.986(0.187)$ & $1.086(0.285)$ & 0.009 \\
Atherosclerotic plaques, score & $0.78(0.85)$ & $1.08(0.91)$ & $0.071(\mathrm{NS})$ \\
\hline
\end{tabular}

Note: to calculate the score for atherosclerotic plaques in carotid arteries, the 4-point scale was used ( 0 , no plaques; 1-2, lesions occluding up to $10 \%$ or $10 \%-30 \%$ lumen diameter, respectively; 3 , plaques occluding > $30 \%$ lumen diameter)[17]. NS: not significant; MetS: metabolic syndrome

HDL cholesterol correlated with heteroplasmy m.1555A $>\mathrm{G}(r=0.151, P=0.037)$ and $\mathrm{m} .14459 \mathrm{G}>\mathrm{A}(r=$ -0.165, $P=0.022)$. Fasting blood sugar correlated with m.3336T $>C$ heteroplasmy $(r=0.180, P=0.013)$, and m.14846G $>$ A heteroplasmy $(r=0.142, P=0.050)$. None of the mutations correlated with waist circumference or diastolic blood pressure.

Linear regression analysis was performed to explain the variability of integral MetS index by the presence of heteroplasmic mtDNA mutations. The linear regression model explained $14.2 \%$ variability of integral MetS index $(R=0.377, P=0.003)$. The most potent explanatory variable was T3336C heteroplasmy $(P=0.003)$; other mutations did not reach explanatory level by statistical significance.

As mentioned above, the difference between MetS-free study participants and MetS patients reached statistical significance for BMI, waist circumference, systolic and diastolic BP, hypertension and left ventricular hypertrophy, Type 2 diabetes prevalence and family history, triglycerides, HDL cholesterol, fasting glucose, integral MetS index, mean and mean-maximum cIMT, plaque score, and heteroplasmy for m.3336C $>\mathrm{T}$ and $\mathrm{m} .14846 \mathrm{G}>\mathrm{A}$ mutations. Therefore, the null-hypothesis on the absence of difference was rejected with more than $95 \%$ probability, and the groups size was sufficient to demonstrate the observed differences. We have also checked the statistical power of the study for those mtDNA mutations, for which 
Table 4. Heteroplasmy level of mtDNA (\% of mutant allele) in leukocytes from MetS patients and MetS-free study participants

\begin{tabular}{lccc}
\hline Heteroplasmic mtDNA mutation & MetS-free study participants, $\boldsymbol{n}=\mathbf{1 7 6}$ & MetS patients, $\boldsymbol{n}=\mathbf{4 4}$ & $\boldsymbol{P}$ for the difference \\
\hline m.652delG & $2.8(7.7)$ & $5.3(9.0)$ & NS \\
m.1555A $>$ G & $17.1(11.6)$ & $14.3(7.4)$ & NS \\
m.3256C>T & $22.6(14.3)$ & $26.0(16.1)$ & NS \\
m.3336T>C & $7.9(5.1)$ & $13.1(15.5)$ & 0.036 \\
m.5178C >A & $15.4(9.9)$ & $16.7(13.3)$ & NS \\
m.12315G > & $22.0(12.5)$ & $25.3(12.3)$ & NS \\
m.13513G $>$ A & $24.6(19.1)$ & $20.3(17.1)$ & NS \\
m.14459G $>$ A & $17.2(12.9)$ & $17.2(12.1)$ & NS \\
m.14846G $>$ A & $14.6(11.5)$ & $20.8(13.7)$ & 0.047 \\
m.15059G $>$ A & $6.2(5.7)$ & $6.7(5.8)$ & NS \\
\hline
\end{tabular}

NS: not significant; MetS: metabolic syndrome; mtDNA: mitochondrial DNA

the differences in heteroplasmy levels did not reach statistical significance. Statistical power varied from $28 \%$ to $76 \%$; the analysis has shown that the sample size was insufficient to exclude type 2 error for mutations m.652delG, m.1555A $>$ G, m.12315G $>$ A, and m.13513G $>$ A. For all remaining mutations, the increase of sample size turned unreasonable, since it could not lead to statistically significant between-group differences.

\section{DISCUSSION}

In this study, we have found that only a few mtDNA mutations previously described as atherosclerosis-related ones $^{[13-18]}$, are also associated with MetS. Namely, these are m.3336T>C mtDNA mutation and, to some extent the m.652delG mutation. Since MetS is a constellation of several risk factors, the observed associations should be explained by correlations with single cardiometabolic risk factors, that is the higher the correlation of risk factors with mtDNA heteroplasmy, the higher the probability of association with MetS. This seems to be especially true for m.3336T>C mtDNA mutation, which occurs in MT-ND1 gene (encodes subunit 1 of $\mathrm{NADH}$ dehydrogenase). It is known that the m.3336T>C mutation is a silent point mutation, resulting in an ATT to ATC substitution without changing the amino acid sequence of the transcribed protein. The association of $\mathrm{m} .3336 \mathrm{~T}>\mathrm{C}$ variant with metabolic syndrome may be speculatively explained by the linkage with some still unknown mutant haplotype associated with mitochondrial dysfunction. In any case, it is not at present possible to suggest any mechanistic role of m.3336 $>\mathrm{C}$ mutation in the formation of a pathologic phenotype; one can only consider this mtDNA variant as a potential biomarker or even as a bystander. It remains questionable, if this mutation may have something to do with disruption to mitochondrial glutathione redox status due to oxidative stress; the analysis of sequence variation in mitochondrial complex I genes did not describe m.3336 $>\mathrm{C}$ variant as possibly, probably or almost certainly pathogenic one ${ }^{[23]}$. It should be mentioned that because of highly polymorphic nature of mtDNA, the establishing of polymorphic either pathogenic nature of any detected sequence change is still a major difficulty ${ }^{[23]}$.

As for the other mutations, there are some theoretical pathways whereby they may promote metabolic consequences, altering the expression of cardiometabolic risk factors via increased oxidative stress, increased ROS production, and mitochondrial dysfunction, which may be generally described as the inhibition of mitochondrial consumption of oxygen, the changes in the mitochondrial membrane potential, and the reduction of adenosine triphosphate levels due to an disbalanced intake and expenditure of energy ${ }^{[24]}$.

Mutation m.652delG (guanine deletion at position 652) in MT-RNR1 gene affects the function of $12 \mathrm{~S}$ ribosomal RNA, even leading to complete mitochondrial dysfunction due to decrease in expression of respiratory chain enzymes, reduction of the amount of these enzymes and increase of oxidative stres ${ }^{[25]}$. Mutation m.1555A $>\mathrm{G}$ in the same gene leads to a single nucleotide substitution, and is known to be associated with mitochondrial deafness and aminoglycoside-induced sensorineural hearing loss ${ }^{[26,27]}$. Interesting, this mutation is also thought to stabilize the ribosome and provide some beneficial effect ${ }^{[20]}$. 
In support of this, within our study, m.1555A $>\mathrm{G}$ heteroplasmy level negatively correlated with systolic blood pressure and positively correlated with HDL cholesterol, thus trending to be associated with lower cardiometabolic risk.

Mutation m.3256C $>\mathrm{T}$ occurring in coding sequence of the MT-TL1 gene (encodes tRNA leucine) leads to impaired protein synthesis due to reduced number of cellular organelles ${ }^{[28,29]}$. This effect can be enhanced by mutation $\mathrm{m} .12315 \mathrm{G}>\mathrm{A}$, which is located in the coding sequence of another gene encoding tRNA leucine, namely, the MT-TL2 gene. So, the impairments in tRNA leucine production may act as a previously unknown mechanism for the development of metabolic abnormalities, with the m.12315G>A mutation known to be associated with mitochondrial encephalomyopathy ${ }^{[30]}$.

Three mutations (m.14459G $>$ A, m.14846G $>$ A, and $\mathrm{m} .15059 \mathrm{G}>\mathrm{A}$ ) occur in coding regions of two genes responsible for the synthesis of subunit 6 of NADH dehydrogenase and cytochrome B (MT-ND6 and MT-CYB genes, respectively). The impairments of these respiratory chain enzymes can attenuate NADH oxidation and ubiquinone (CoQ) reduction and promote oxidative stress. Mutation m.14459G>A leads to alanine to valine substitution in a conserved region of ND6 protein, and is associated with several mitochondrial disorders (Leber's hereditary visual neuropathy, hereditary ocular neuropathy, dysfunction of basal ganglia, atrophy of visual nerve, musculospastic syndrome and encephalopathy $)^{[31,32]}$. Mutations m.14846G $>A$ and $\mathrm{m} .15059 \mathrm{G}>\mathrm{A}$ induce the damage of cytochrome B. The former (glycine to serine substitution at position 34) affects intermediate transfer of electrons in mitochondrial respiratory chains. The latter (glycine to stop codon substitution at position 190) stops translation and leads to the loss of 244 amino acids at C-terminal of protein. Both mutations reduce enzymatic function of cytochrome $\mathrm{B}$, and are associated with mitochondrial disorders in various myopathies ${ }^{[33,34]}$.

The list of mtDNA mutations associated with metabolic and atherosclerotic diseases obviously needs to be supplemented with new variants deserving further investigation. As an example, the T/C substitution at position 16189 in the hypervariable D-loop of the control region is suspected to be associated with various multifactorial diseases; the frequency of this mtDNA variant in patients with coronary artery disease and type 2 diabetes mellitus was higher as compared to healthy individuals of Middle European descent in Austria ${ }^{[35]}$.

Defective cell metabolism is considered as the main mechanism of MetS development, due to the disbalance of nutrient intake and utilization for energy ${ }^{[36]}$. It is supposed that decreased fatty acid oxidation, in turn, increases the accumulation of fatty acyl-CoAs and other fat-derived molecules in various organs and cells, this causing the inhibition of insulin signaling, resulting in hyperinsulinemia, which targets various organs and tissues in metabolic diseases. It is known that mtDNA mutations correlate with increased ROS production in cells ${ }^{[37,38]}$. Thus, oxidative stress induced by genetic factors, aging and mitochondrial biogenesis can affect mitochondrial function, leading to insulin resistance and related pathological conditions, such as MetS, Type 2 diabetes mellitus, cardiovascular and atherosclerotic disease ${ }^{[39-42]}$. However, it is still not clear whether mitochondrial dysfunction is one of the primary causes of cardiometabolic disturbances, or merely a secondary effect ${ }^{[43]}$.

Beyond doubt, this study has certain limitations. First, the atherosclerotic state of study participants was evaluated only by carotid ultrasonography and cIMT measurement, the latter being widely used as a surrogate marker for detecting subclinical atherosclerosis for risk prediction and disease progress ${ }^{[44]}$. Ultrasound-derived atherosclerosis metrics are independent predictors of cardiovascular events and improve risk prediction when added atop of conventional cardiovascular risk factors ${ }^{[4]}$. However, it can be argued that cIMT and carotid plaque measurement are insufficient for the diagnostics of systemic atherosclerosis, and therefore may be supplemented by other diagnostic techniques, like computer tomography or magnetic resonance imaging. However, it could be true if only these methods possessed much better resolution to 
measure the plaque size and/or the intima-media thickness in a quantitative manner. In our study, the principal point was the use of cIMT as the continuous variable, which allows further correlation and regression analyses. Second, statistical analysis has shown that the sample size was insufficient to exclude type 2 error for mutations m.652delG, m.1555A $>\mathrm{G}, \mathrm{m} .12315 \mathrm{G}>\mathrm{A}$, and $\mathrm{m} .13513 \mathrm{G}>\mathrm{A}$. It means that the nullhypothesis on the presence of the differences for these variables in the case when we failed to observe them in our study due to insufficient sample size, cannot be rejected.

In conclusion, the phenotype of MetS in this study was not explained directly by atherosclerosis-related mtDNA variants, or the known proatherogenic mtDNA mutations. By far, it may be hypothesized that mtDNA-related mechanisms in atherosclerosis and MetS are different, in spite of the similarity of several phenotypic characteristics. However, there is a convincing evidence that mtDNA damage may play a mechanistic role in arising and development of cardiovascular and metabolic disorders. Complexity of the MetS phenotype should be taken into account, as well as the uncertainty about the common pathogenic mechanisms explaining the clustering of metabolic abnormalities, and modulating effects of lifestyle factors ${ }^{[46]}$. The conventional role of modified low density lipoprotein in the development of atherosclerosis should be also assumed ${ }^{[47,48]}$. It may be speculated that the sets of mtDNA mechanistic biomarkers may be different in MetS and atherosclerosis. As an example, in the East Finland Founder Population Hypertension Genetics Study (EFFGE) the whole mtDNA was sequenced in 1,204 adult subjects, and the variants with the strongest association with obesity were retested in 1,656 subjects from the Young Finns Study. At least 7 novel mtDNA variants were found to be associated with body mass index, and 6 - with obesity (body mass index above $30 \mathrm{~kg} / \mathrm{m}^{2}$ ) (J.T. Salonen, personal communication). Interestingly, none of these mtDNA variants were ever shown to be associated with atherosclerosis or its clinical manifestations (or, more correct, tested for such association). So, the search for genetic determinants of the MetS remains the challenge.

\section{DECLARATIONS}

\section{Authors' contributions}

Concept of the study, general coordination and supervision of the research project, data analysis, statistical analysis, and manuscript writing: Sobenin IA

Concept elaboration and discussion, and manuscript editing: Salonen JT

MtDNA genotyping: Khasanova ZB, Sinyov VV, Melnichenko AA

Patients' recruitment, clinical examination and clinical data acquisition: Kirichenko TV, Prokudina AI, Orekhova VA, Grechko AV

\section{Availability of data and materials}

Not applicable.

\section{Financial support and sponsorship}

The study was supported by the Russian Science Foundation (Grant \#14-14-01038).

\section{Conflicts of interest}

All authors declared that there are no conflicts of interest.

\section{Ethical approval and consent to participate}

This study was kept in accordance with the Helsinki Declaration of 1975 as revised in 1983, 2008 and 2013. It was approved by the local ethics committee of the Institute for Atherosclerosis Research, Skolkovo Innovation Center, Moscow, Russia. All participants gave their written informed consent prior to their inclusion in the study.

\section{Consent for publication}

Not applicable. 


\section{Copyright}

(c) The Author(s) 2019.

\section{REFERENCES}

1. Zabaneh D, Balding DJ. A genome-wide association study of the metabolic syndrome in Indian Asian men. PLoS One 2011;5:e11961.

2. Kraja AT, Vaidya D, Pankow JS, Goodarzi MO, Assimes TL, et al. A bivariate genome-wide approach to metabolic syndrome: STAMPEED consortium. Diabetes 2011;60:1329-39.

3. Kristiansson K, Perola M, Tikkanen E, Kettunen J, Surakka I, et al. Genome-wide screen for metabolic syndrome susceptibility Loci reveals strong lipid gene contribution but no evidence for common genetic basis for clustering of metabolic syndrome traits. Circ Cardiovasc Genet 2012;5:242-9.

4. Avery CL, He Q, North KE. A phenomics-based strategy identifies loci on APOC1, BRAP, and PLCG1 associated with metabolic syndrome phenotype domains. PLoS Genet 2011;7:e1002322.

5. Alberti KG, Zimmet PZ. Definition, diagnosis and classification of diabetes mellitus and its complications. Part 1: diagnosis and classification of diabetes mellitus provisional report of a WHO consultation. Diabet Med 1998;15:539-53.

6. Balkau B, Charles MA. Comment on the provisional report from the WHO consultation. european group for the study of insulin resistance (EGIR). Diabet Med 1999;16:442-3.

7. Expert Panel on Detection, Evaluation, and Treatment of High Blood Cholesterol in Adults. Executive summary of the third report of the national cholesterol education program (NCEP) expert panel on detection, evaluation, and treatment of high blood cholesterol in adults (Adult Treatment Panel III). JAMA 2001;285:2486-97.

8. Grundy SM, Brewer HB, Cleeman JI, Smith SC Jr, Lenfant C, et al. Definition of metabolic syndrome: report of the National, Heart, Lung, and Blood Institute/American Heart Association conference on scientific issues related to definition. Circulation 2004;109:433-8.

9. Alberti KG, Zimmet P, Shaw J. IDF epidemiology task force consensus group. The metabolic syndrome - a new worldwide definition. Lancet 2005;366:1059-62.

10. Alberti KG, Eckel RH, Grundy SM, Zimmet PZ, Cleeman JI, et al. Harmonizing the metabolic syndrome: a joint interim statement of the international diabetes federation task force on epidemiology and prevention; national heart, lung, and blood institute; American heart association; world heart federation; international atherosclerosis society; and international association for the study of obesity. Circulation 2009;120:1640-5.

11. Rankinen T, Sarzynski MA, Ghosh S, Bouchard C. Are there genetic paths common to obesity, cardiovascular disease outcomes, and cardiovascular risk factors? Circ Res 2015;116:909-22.

12. Sazonova M, Budnikov E, Khasanova Z, Sobenin I, Postnov A, et al. Studies of the human aortic intima by a direct quantitative assay of mutant alleles in the mitochondrial genome. Atherosclerosis 2009;204:184-90.

13. Sobenin IA, Sazonova MA, Postnov AY, Bobryshev YV, Orekhov AN. Mitochondrial mutations are associated with atherosclerotic lesions in the human aorta. Clin Dev Immunol 2012;2012:832464.

14. Sobenin IA, Sazonova MA, Postnov AY, Bobryshev YV, Orekhov AN. Changes of mitochondria in atherosclerosis: possible determinant in the pathogenesis of the disease. Atherosclerosis 2013;227:283-8.

15. Sazonova MA, Sinyov VV, Barinova VA, Ryzhkova AI, Zhelankin AV, et al. Mosaicism of mitochondrial genetic variation in atherosclerotic lesions of the human aorta. Biomed Res Int 2015;2015:825468.

16. Sobenin IA, Sazonova MA, Ivanova MM, Zhelankin AV, Myasoedova VA, et al. Mutation C3256T of mitochondrial genome in white blood cells: novel genetic marker of atherosclerosis and coronary heart disease. PLoS One 2012;7:e46573.

17. Sobenin IA, Sazonova MA, Postnov AY, Salonen JT, Bobryshev YV, et al. Association of mitochondrial genetic variation with carotid atherosclerosis. PLoS One 2013;8:e68070.

18. Sazonova MA, Chicheva MM, Zhelankin AV, Sobenin IA, Bobryshev YV, et al. Association of mutations in the mitochondrial genome with the subclinical carotid atherosclerosis in women. Exp Mol Pathol 2015;99:25-32.

19. Sinyov VV, Sazonova MA, Ryzhkova AI, Galitsyna EV, Melnichenko AA, et al. Potential use of buccal epithelium for genetic diagnosis of atherosclerosis using mtDNA mutations. Vessel Plus 2017;1:145-50.

20. Sazonova MA, Ryzhkova AI, Sinyov VV, Galitsyna EV, Orekhova VA, et al. New markers of atherosclerosis: a threshold level of heteroplasmy in mtDNA mutations. Vessel Plus 2017;1:182-91.

21. Salonen R, Nyyssönen K, Porkkala E, Rummukainen J, Belder R, et al. Kuopio Atherosclerosis Prevention Study (KAPS). A population-based primary preventive trial of the effect of LDL lowering on atherosclerotic progression in carotid and femoral arteries. Circulation 1995;92:1758-64.

22. Sobenin IA, Surnin SA, Karagodin VP, Miasoedova VA, Kirichenko TV, et al. Variability of intima-media thickness of the common carotid arteries in Moscow city population without clinical symptoms of atherosclerosis. Ter Arkh 2011;83:58-62.

23. Mitchell AL, Elson JL, Howell N, Taylor RW, Turnbull DM. Sequence variation in mitochondrial complex I genes: mutation or polymorphism? J Med Genet 2006;43:175-9.

24. Pieczenik SR, Neustadt J. Mitochondrial dysfunction and molecular pathways of disease. Exp Mol Pathol 2007;83:84-92.

25. Springer MS, Douzery E. Secondary structure and patterns of evolution among mammalian mitochondrial $12 \mathrm{~S}$ rRNA molecules. J Mol Evol 1996;43:357-73.

26. Shen SS, Liu C, Xu ZY, Hu YH, Gao GF, et al. Heteroplasmy levels of mtDNA1555A $>$ G mutation is positively associated with diverse phenotypes and mutation transmission in a Chinese family. Biochem Biophys Res Commun 2012;420:907-12.

27. Ealy M, Lynch KA, Meyer NC, Smith RJ. The prevalence of mitochondrial mutations associated with aminoglycoside-induced sensorineural hearing loss in an NICU population. Laryngoscope 2011;121:1184-6. 
28. Rossmanith W, Karwan RM. Impairment of tRNA processing by point mutations in mitochondrial tRNA(Leu) (UUR) associated with mitochondrial diseases. FEBS Lett 1998;433:269-74.

29. Krag TO, Hauerslev S, Jeppesen TD, Duno M, Vissing J. Muscle regeneration in mitochondrial myopathies. Mitochondrion 2013;13:6370.

30. Valente L, Piga D, Lamantea E, Carrara F, Uziel G, et al. Identification of novel mutations in five patients with mitochondrial encephalomyopathy. Biochim Biophys Acta 2009;1787:491-501.

31. Lim BC, Park JD, Hwang H, Kim KJ, Hwang YS, et al. Mutations in ND subunits of complex I are an important genetic cause of childhood mitochondrial encephalopathies. J Child Neurol 2009;24:828-32.

32. Funalot B, Reynier P, Vighetto A, Ranoux D, Bonnefont JP, et al. Leigh-like encephalopathy complicating Leber's hereditary optic neuropathy. Ann Neurol 2002;52:374-7.

33. Tarnopolsky MA, Baker SK, Myint T, Maxner CE, Robitaille J, et al Clinical variability in maternally inherited leber hereditary optic neuropathy with the G14459A mutation. Am J Med Genet A 2004;124A:372-6.

34. Andreu AL, Bruno C, Dunne TC, Tanji K, Shanske S, et al. A nonsense mutation (G15059A) in the cytochrome b gene in a patient with exercise intolerance and myoglobinuria. Ann Neurol 1999;45:127-30.

35. Mueller EE, Eder W, Ebner S, Schwaiger E, Santic D, et al. The mitochondrial T16189C polymorphism is associated with coronary artery disease in Middle European populations. PLoS One 2011;6:e16455.

36. Gastaldi G, Giacobino JP, Ruiz J. Metabolic syndrome, a mitochondrial disease? Rev Med Suisse 2008;4:1387-8, 1390-1. (in French)

37. Indo HP, Davidson M, Yen HC, Suenaga S, Tomita K, et al. Evidence of ROS generation by mitochondria in cells with impaired electron transport chain and mitochondrial DNA damage. Mitochondrion 2007;7:106-18.

38. Ishikawa K, Takenaga K, Akimoto M, Koshikawa N, Yamaguchi A, et al. ROS-generating mitochondrial DNA mutations can regulate tumor cell metastasis. Science 2008;320:661-4.

39. Maassen JA, 'T Hart LM, van Essen E, Heine RJ, Nijpels G, et al. Mitochondrial diabetes: molecular mechanisms and clinical presentation. Diabetes 2004;53:S103-9.

40. Choksi KB, Boylston WH, Rabek JP, Widger WR, Papaconstantinou J. Oxidatively damaged proteins of heart mitochondrial electron transport complexes. Biochim Biophys Acta 2004;1688:95-101.

41. Smith SC Jr. Multiple risk factors for cardiovascular disease and diabetes mellitus. Am J Med 2007;120:S3-11.

42. Sowers JR. Insulin resistance and hypertension. Am J Physiol Heart Circ Physiol 2004;286:H1597-602.

43. Sorriento D, Pascale AV, Finelli R, Carillo AL, Annunziata R, et al. Targeting mitochondria as therapeutic strategy for metabolic disorders. ScientificWorldJournal 2014;2014:604685.

44. Ho SS. Current status of carotid ultrasound in atherosclerosis. Quant Imaging Med Surg 2016;6:285-96.

45. Polak JF, Szklo M, Kronmal RA, Burke GL, Shea S, et al. The value of carotid artery plaque and intima-media thickness for incident cardiovascular disease: the multi-ethnic study of atherosclerosis. J Am Heart Assoc 2013;2:e000087.

46. Stančáková A, Laakso M. Genetics of metabolic syndrome. Rev Endocr Metab Disord 2014;15:243-52.

47. Sobenin IA, Galitsyna EV, Grechko AV, Orekhov AN. Small dense and desialylated low density lipoprotein in diabetic patients. Vessel Plus 2017;1:29-37.

48. Orekhov AN, Sobenin IA. Modified lipoproteins as biomarkers of atherosclerosis. Front Biosci (Landmark Ed) 2018;23:1422-44. 